\title{
Recent Advances in Soft E-Textiles
}

\section{Kunal Mondal}

Department of Chemical \& Biomolecular Engineering, North Carolina State University, Campus Box 7905, Raleigh, NC 27695-7905, USA; kmondal@ncsu.edu; Tel.: +1-(919)-260-9449

Received: 15 March 2018; Accepted: 10 April 2018; Published: 11 April 2018

\begin{abstract}
E-textiles (electronic textiles) are fabrics that possesses electronic counterparts and electrical interconnects knitted into them, offering flexibility, stretchability, and a characteristic length scale that cannot be accomplished using other electronic manufacturing methods currently available. However, knitting is only one of the technologies in e-Textile integration. Other technologies, such as sewing, embroidery, and even single fiber-based manufacture technology, are widely employed in next-generation e-textiles. Components and interconnections are barely visible since they are connected intrinsically to soft fabrics that have attracted the attention of those in the fashion and textile industries. These textiles can effortlessly acclimatize themselves to the fast-changing wearable electronic markets with digital, computational, energy storage, and sensing requirements of any specific application. This mini-review focuses on recent advances in the field of e-textiles and focuses particularly on the materials and their functionalities.
\end{abstract}

Keywords: textiles; smart fabrics; smart sensing; fibers; electronic textiles

\section{Introduction}

E-textiles and associated technologies are experiencing a tremendous growth and expansion [1-14]. New step-by-step textiles are entering the market with an exceptional amount of potential applications, such as proximity sensors [15], heat control [16], humidity [17], optical guides [18], the realization of light diffusers [19], and biophysical sensing abilities [20-24]. Such functionalities are beneficial for numerous applications in such fields as environmental science, athletics and sports, healthcare, space investigation, and games and entertainment [25-29]. The advancement in digital electronics facilitates the continuous integration of required functionalities, which confronts over a potential bionic stigma and enhances the demand for e-textiles $[30,31]$.

E-textiles are unique in that they are ultra-lightweight, stretchable and flexible, intrinsically warm, and conformable [32]. E-textiles have been used in micro/nanofiber-based apparel with integrated electronics and have assumed body-attachable forms; their key constituents with adjustable designs thus have been significantly commercialized [33,34].

Using the knowledge in digital electronics and information technologies in textiles with smart fabrics in clothing creates more exciting opportunities for e-textiles. Based on the various approaches implemented, e-textiles are also known as intelligent textiles, smart textiles, techno-textiles, wearable computers, and wearable electronics [35,36]. Multidisciplinary atmosphere for e-textiles is illustrated in Figure 1. 


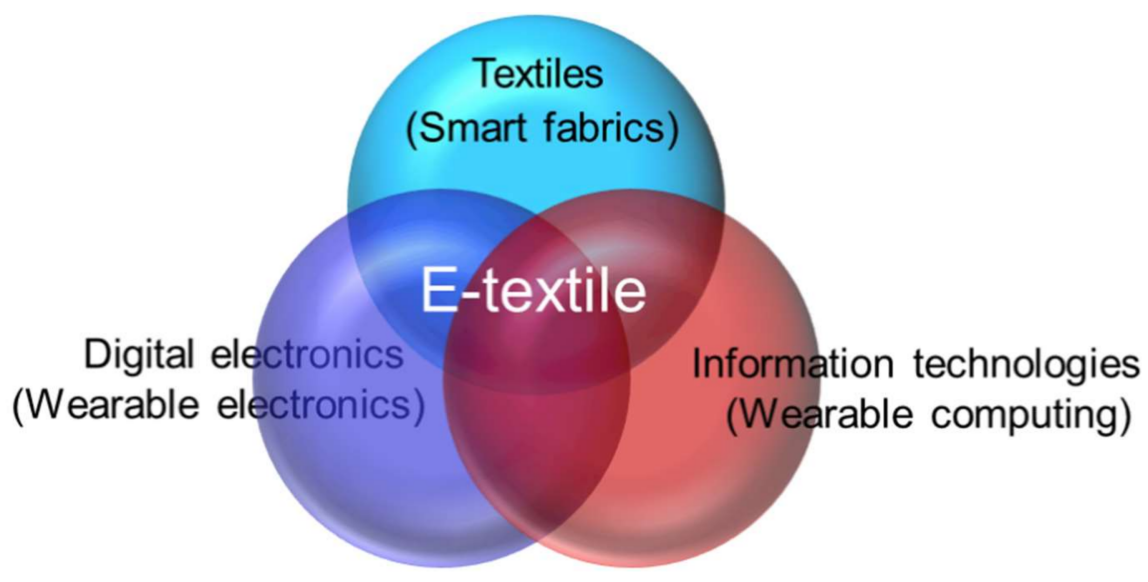

Figure 1. Multidisciplinary approach to e-textiles.

\section{Materials for E-Textiles}

The contribution of nanotechnology in the advancement of new materials for advance textile is remarkable $[37,38]$. The existing functional properties in textile fabrics can be improved using nanomaterials, but textiles can also be produced with new properties or, in a single textile material, with an amalgamation of various functions [39]. From a materials standpoint, electrical conductivity can be imparted to textile assemblies at any of the hierarchical levels using: (i) metals; (ii) intrinsically conducting polymers; or (iii) conducting-particle/polymer (micro or nano) composites at loading levels just above the percolation threshold. These materials could be cast off in the form of fibers or in any other appropriate form, such as solder for routing circuits, or as a printed layer. It is worth stating here that, at present, there are many commercial soft and flexible conductors in many of these arrangements on the market.

Coating the surface of fabrics with nanoparticles can produce surfaces that are oil- and water-repellant, flame-retardant, antimicrobial, ultra-violet-light blocking, antistatic, wrinkle-resistant, and self-cleaning [40-47]. Figure 2 describes the broad spectrum of application of nanoparticles and the associated technologies in e-textiles.

Numerous approaches have also been investigated to yield electrically conductive fabrics, including metallized textiles, conductive polymer-based textiles, and composite nanoparticle coatings, for e-textiles. Among such fabrics is nanocarbon-based conductive textiles. The integration of graphene, carbon nanotubes (CNTs), and carbon nano/micro fibers (CNFs) with textiles is worth mentioning [48-52]. Electrospinning and melt spinning techniques have been used to produce polymeric nano/micro fibers, which have thereafter been carbonized to fabricate conducting carbon fabrics. In some cases, electrospinning was performed on textiles to produce wearable electronics. For example, Huang et al. [53] electrospun carbon nanowebs on metallic textiles to produce high-capacitance supercapacitor fabrics. They directly electrospun multi-walled carbon nanotubes (MWCNTs) onto wearable nickel-coated cotton fabrics. Joseph et al. [54] presented a unique method of integrating substrate-free electrospinning with textile technology. A completely new collector was designed that yielded a pressure-driven, localized cotton-wool structure in free space, from which high strength and continuous yarns were drawn. The fabrication of conductive, flexible, and durable textiles with reduced graphene oxide (RGO) on nylon-6 yarns, cotton yarns, polyester yarns, and nonwoven textile fabrics via a facile preparation method has been reported recently by Prof. Byung Hoon Kim's group [55]. They also solved the problem of adhesion between GO and textiles using bovine serum albumin (BSA) proteins, which serve as universal adhesives for any textile, regardless of their surface conditions. 
The inadequate durability of those coatings of nanoparticles on textiles and the stability of several properties induced by nanoparticles are major obstacles that hinder the commercialization of e-textiles [56].

Many researchers are actively involved in this field to solve this. For example, Prof. Yun and his co-workers at Harvard University, USA, have been working on textiles integrated with electronic and photonic nanomaterials for applications in the areas of digital displays, sensing, and drug delivery within the background of their performance, durability, and connectivity [57]. Figure 3 depicts ideas of applications of nanotechnology in e-textiles. Recently, Du et al. [58] reported on a highly washable e-textile fabricated by ultrasonically nanosoldering carbon nanotubes onto polymer fibers. They reported that their fabricated CNT e-textiles fabrics have good washability. The CNTs remain on the fiber surface even after forceful mechanical washing in water for several hours, and the conductance of the textile slightly reduces.

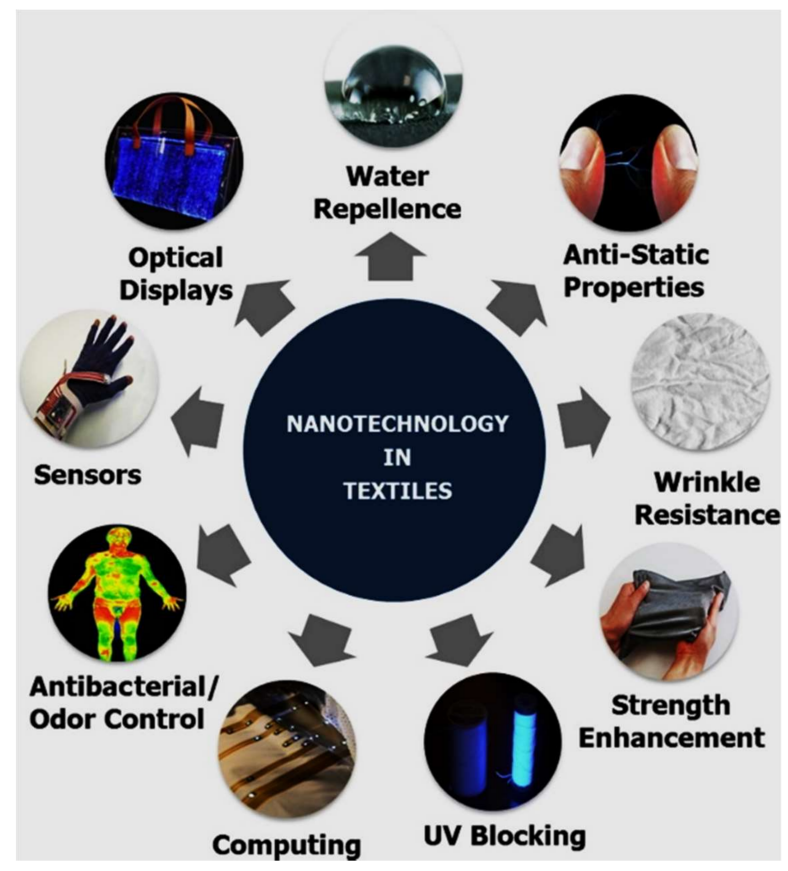

Figure 2. Various application of nanotechnology in e-textiles. Reprinted with permission from [57]. Copyright (2016) American Chemical Society.

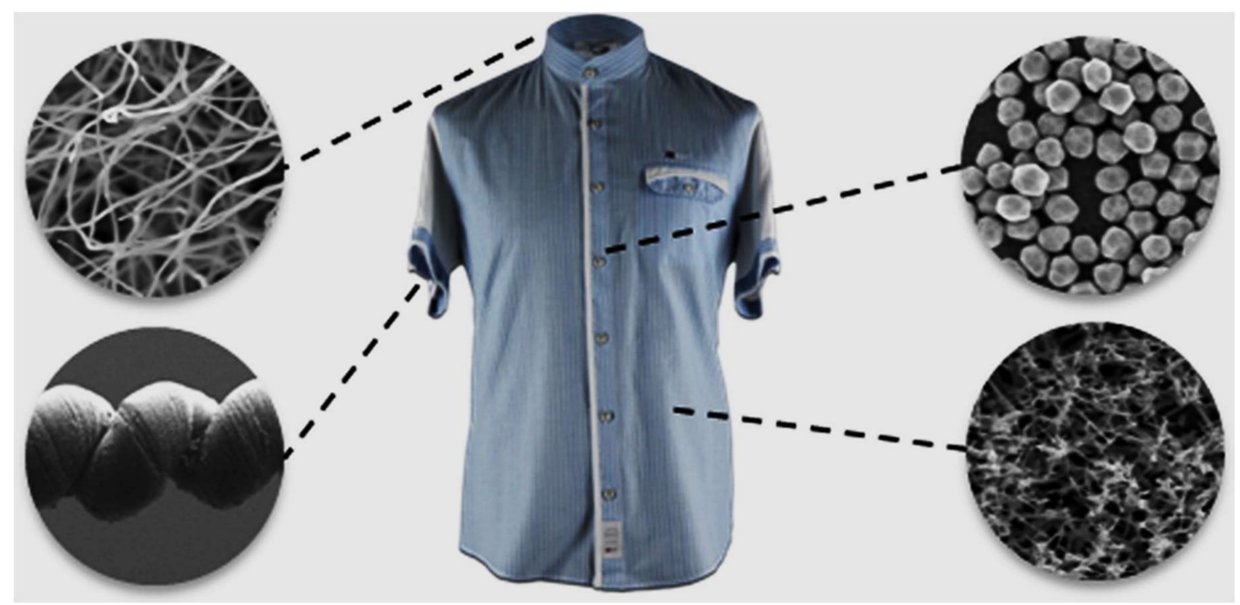

Figure 3. Nanotechnology in e-textiles: An overview. Reprinted with permission from [57]. Copyright (2016) American Chemical Society. 


\section{Textiles Integrated with Electronics}

The superior electrical conductivity of conducting polymers, carbon nanotubes, and graphene makes them live options for producing textiles that allow for an integration of sensors and actuators with fabrics $[59,60]$. The addition of electronic components to these fabrics would create a fully new range of functional clothing. Optical light emitting diodes (OLEDs), nanoelectronics, conducting liquid metals, etc., in fiber form could lead to revolutionary applications by integrating optical, optoelectronic, flexible, and stretchable devices with textiles [61,62]. Recently, Levi's musical jacket prepared by the Media Lab at Massachusetts Institute of Technology (MIT), USA, includes a flexible and durable embroidered fabric keyboard. It is developed with a composite fabric made from polyester and low conductive stainless-steel thread consuming ordinary embroidery methods. They reported that this keyboard is very reactive to touch and transforms a usual denim jacket into a wearable musical gadget that permits the owner to play notes, chords, and rhythms [35,36].

A multifunctional body-motion sensors and user-interface (UI) strategies in textile platform (as shown in Figure 4) using polymerized poly(3,4-ethylenedioxythiophene) (PEDOT)-coated fibers has been developed by Prof. Kim's research group in South Korea [63]. Upon integration of PEDOT fibers in a fabric through a fiber pattern design, multifunctional textile sensors, such as highly sensitive and consistent strain sensors, body-motion monitoring sensors, touch sensors, and multilevel strain recognition UI devices, have been constructed. However, motion capture using fabrics is an old and recurring topic in smart textiles [64-66]. It is also one of the current limitations of e-textiles owing to their bulky electronics, batteries, and rigid interconnection. Currently, many new studies are focusing on its solution; nanocomposites and carbon-based fabrics are thus attracting substantial attention [67-69].

Intergradation of photonic materials with optoelectronics in textile fibers makes it possible for the clothes to change color in response to ambient conditions such as heat, moisture, external stimulating light, airborne pollutants, pollen, or even dust. Additionally, coatings of holographic films and optical fibers with periodic multilayered dielectric materials on textiles offers a 3D visual effect and an angle of observation that is sensitive, colorful, and highly reflective.

Wearable communication is also gaining immense interest recently [70-73]. Textile antennas are essential components in this area that cover sensing, and wireless communication functionalities even though being integrated inside or within clothes [74,75]. The available large area in textiles can be explored to install multiple antennas along with other electronic circuitry. To make the best use of the antenna's area, the batteries or energy harvesters can be placed on top of the radiating patch. However, when incorporating the flexible textile wireless communication modules inside the clothes, the device will also be subjected to deformation and distortion owing to activities and movements by the user, producing crumpling, stress, strain, and bending. An enthusiastic design technique is thus essential to secure a stable and reliable antenna performance in these circumstances. Additionally, the selection of materials for textile antennas that offers both good radiation characteristics and great user comfort is critical. The materials should possess conductive as well as insulating parts, and a suitable fabrication method is needed to incorporate an antenna topology to the textiles. Interestingly, to overcome the discrepancy in antenna performance in diverse environmental surroundings, hydrophobic fabrics that show minimum moisture regain must be selected [76].

There are mainly three types of textile antenna fabrication techniques available in the market which pattern the conductive portions and connect them to the insulating antenna portions. The modest approach involves knitting, integrating, or embroidering copper tape, conducting wires (such as silver or aluminum), or conductive yarns into a slice of clothing $[77,78]$. The other widespread technique comprises the incorporation of e-textiles (usually copper- or copper-nickel-plated nonwoven fabrics) with textile fabrics by thermally activated thermal sheets [79]. Lastly, additive manufacturing techniques, such as screen or ink-jet printing and 3D printing, may be applied to configure the antenna, reflector, and ground plane on the textiles [80-82]. Recently, a new substrate waveguide technique was 
designed for the production of wearable antenna entirely from textiles [83]. This is a well-established method of constructing waveguides in (multilayered) high-frequency laminates.

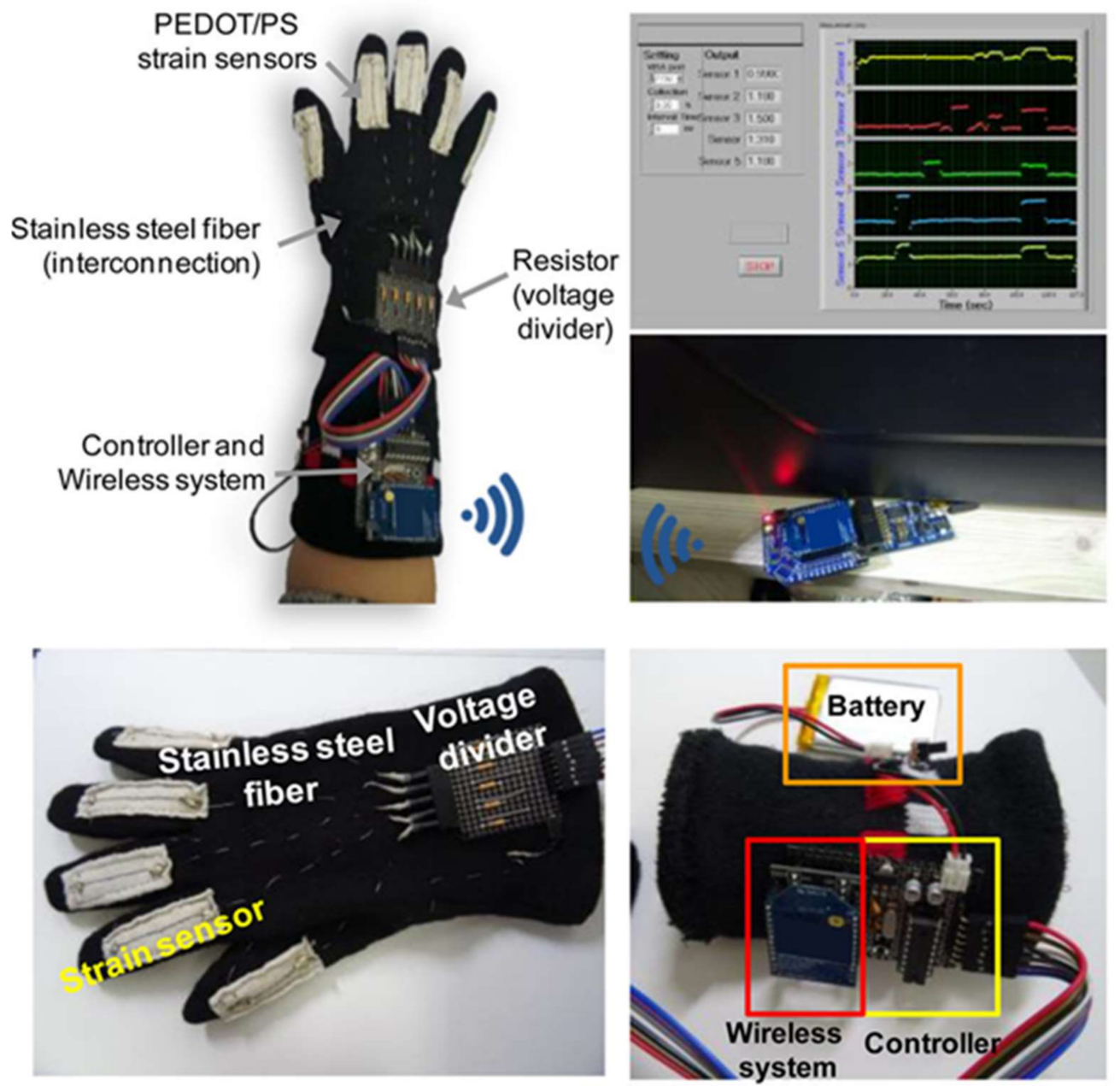

Figure 4. Digital images of a textile-based wearable user-interface device which contains five poly(3,4-ethylenedioxythiophene)/polyester PEDOT/PS strain sensors, stainless steel fiber interconnections, a voltage divider configuration, a battery, and a wireless transmission unit. Reprinted with permission from [63]. Copyright (2017) American Chemical Society.

\section{Smart Textiles in Energy Harvest and Storage}

Energy storage is another emerging area where wearable electronic textiles that harvest and use capacitive energy can be used in personalized electronics. Huang et al. [84] reported on soft conductive yarns that were produced using a twist-bundle-drawing technique and were mechanically robust enough to be woven to a fabric by a commercial machine. Then, the yarns were treated with reduced graphene oxide and became conductive. These yarns were then covered with a hierarchical $\mathrm{MnO}_{2}$ nanosheet/polypyrrole thin film structure to fabricate weavable, knittable, and wearable yarn supercapacitors as shown in Figure 5. It is worth mentioning that Jost et al. [85] have published a comprehensive review paper in this area that provides an overview and perspective on textile-based energy storage with a precise emphasis on devices made from textiles or made as fabrics themselves. In addition, Zhai et al. [86], in their review, focused particularly on the design concepts and structures of textile energy storage devices presently explored, including their fabrication strategies. They mainly highlighted the key developments in the creation of 2D (two-dimensional) textile and 1D yarn batteries and supercapacitor electrodes. 

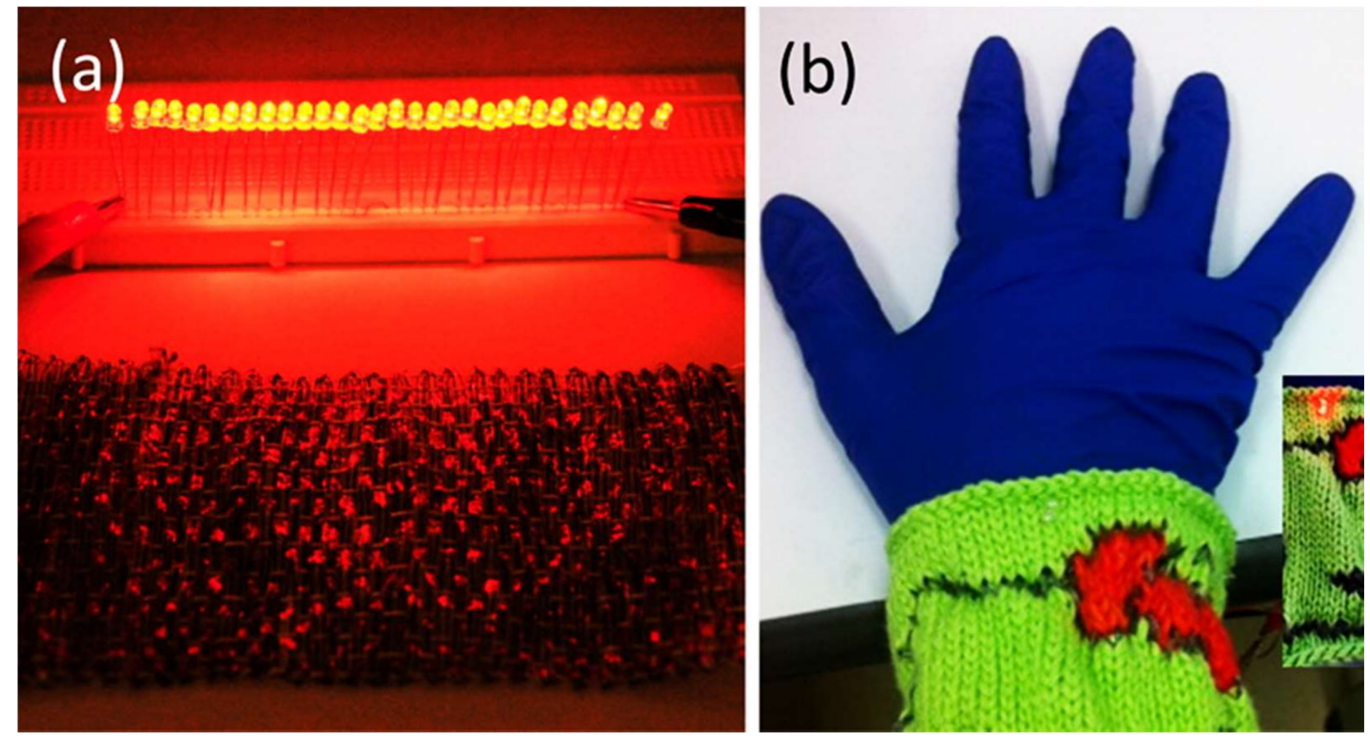

Figure 5. Digital image of an energy storage e-textiles made of conductive yarns. (a) The woven clothes $\left(15 \times 10 \mathrm{~cm}^{2}\right)$ can light 30 LEDs, and (b) a wrist band knitted with a pattern. The inset displays the pattern powering an LED. Reprinted with permission from [84]. Copyright (2015) American Chemical Society.

The most important challenge in this direction is to implement suitable power sources for e-textiles. This issue has been addressed by lightweight fabric consists of carbon nanofibers, carbon nanotubes, and graphene-based supercapacitor electrodes. Additionally, thermoelectric generators, triboelectric nanogenerators, flexible fiber and thin film batteries, and stretchable polypyrrole-based supercapacitors for energy transfer are existing options. In this context, Chai et al. [87] offered an all-solid tailorable energy textile solution that integrates solar energy generation and storage, as shown in Figure 6. The energy storage module in the textile was constructed using symmetric titanium nitride (TiN) nanowire-based fiber supercapacitors (FSCs) that are tailored at different lengths for textile weaving. These units possess ultrafast charging and ultrahigh bending resistance properties, and their large-scale production is easy to realize. Regarding the solar energy harvesting part, they have efficaciously developed all-solid dye-sensitized solar cell (DSSC) fabrics by knitting fiber-shaped photoanodes and counter electrodes together. Figure $6 a-c$ show that the solid-state electrolyte-coated fiber-shaped photoanode is tailorable and wearable, as are FSCs. The digital image in Figure $6 \mathrm{~d}$ shows the as-fabricated DSSC-FSC energy textile embroidered in colored woolen wires. This type of device fabrication route could be an efficient way to engineer various wearable and tailorable energy textile devices. 

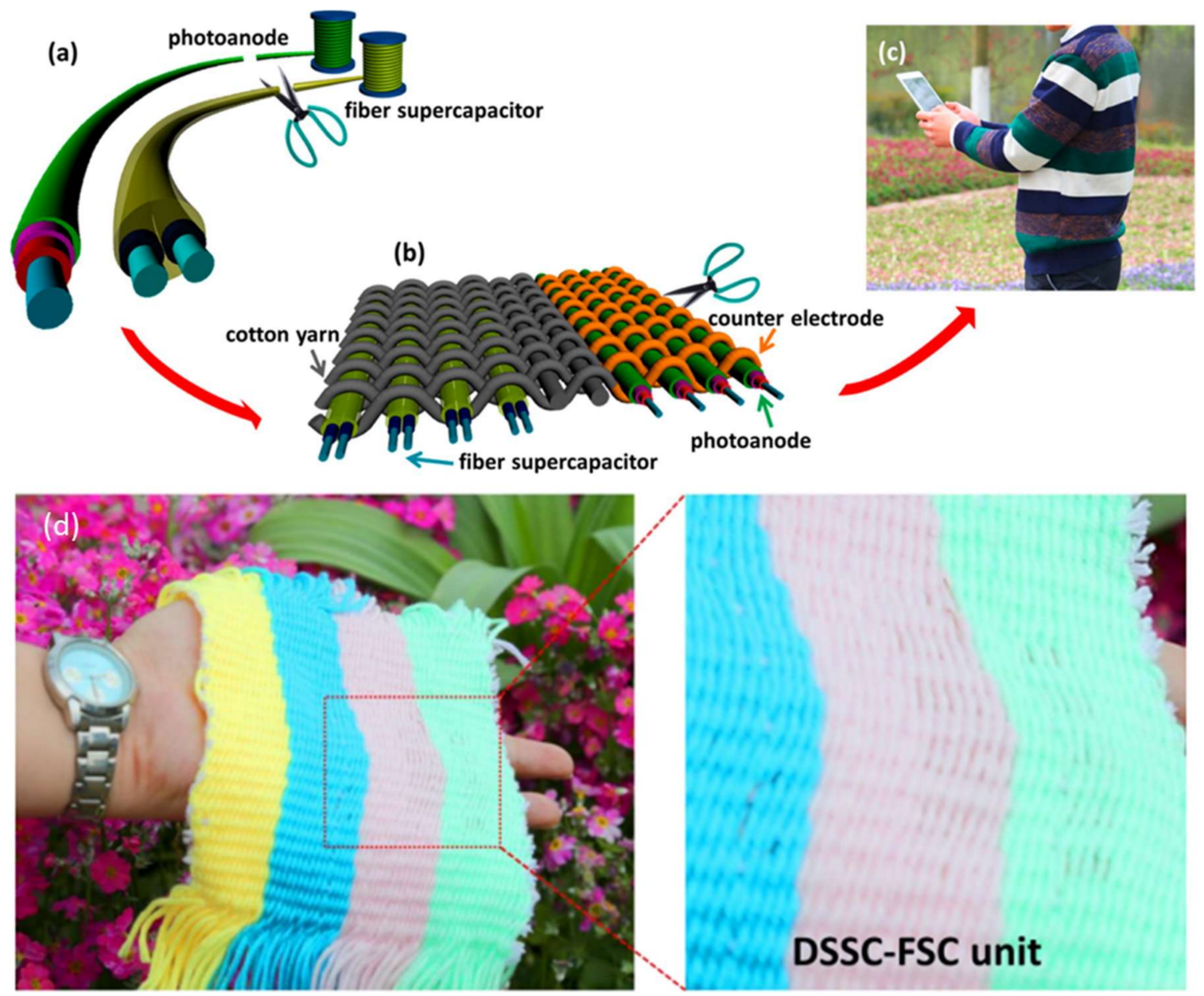

Figure 6. Schematic illustrates the composition and structure ("Thread to Cloth") of the smart energy textile for future smart clothes. (a) The fiber supercapacitor (FSC) and DSSC photoanode "threads" are tailored into different segments, and large-scale fabrication can be easily realized. (b) The textile energy harvest and storage device shaped through weaving, tailoring, and sewing and integrated in FSC and DSSC modules. (c) The scope of wearing smart energy textiles to power a small electronic gadget. (d) A digital photograph of the as-fabricated DSSC-FSC fabric mixed with colored wool wires. Reprinted with permission from reference [87]. Copyright (2016) American Chemical Society.

\section{Stretchable and Flexible Interconnects, and Conductive Textiles}

Deformable, flexible, and stretchable electronic circuits are essential in e-textiles especially for bio-medical applications requiring interconnections between components and devices. One of the main obstructions to the growth of e-textiles is the creation of interconnects within textile fabrics, with hard semiconductor chips and other rigid and/or soft devices and circuits. This problem is aggravated by the requirement of textiles and other materials to survive various mechanical stresses and strains during repetitive use. The vital challenge of making these interconnects includes making them stretchable, flexible, strong, and stable in ambient conditions while guaranteeing sufficient electrical connectivity. Agcayazi et al. [88] recently published an interesting review in this area addressing the technological issues related to textile interconnects and potential research directions and challenges.

Usually, the approach used is to develop electroplated metallic wires in a stretchable polymeric material $[1,15]$. Stretchability in electrical conductors is a necessity that can be fulfilled with different designs. Interconnects made with these materials and techniques coupled with textile fabrics can withstand actual issues concerning the lack of sturdiness in e-textile circuits. In this context, Hu et al. [89] used an interesting methodology to achieve stretchable and highly conductive textiles. 
With a simple "dipping and drying" route consuming single-walled carbon nanotube (SWNT) ink, their group manufactured highly conductive textiles and obtained conductivities of $\sim 125 \mathrm{~S} \cdot \mathrm{cm}^{-1}$ and sheet resistances of less than $1 \Omega$ /sq. In this fashion, such conductive textiles maintain the same stretchability of the regular fabric. To be sure, the porous micro/nanostructure of the textiles helps ease the use from any electrolyte and such porous and stretchable conductors catch an inclusive range of applications in the field of e-textiles. Figure 7 describes the fabrication technique and the conducting fabrics.

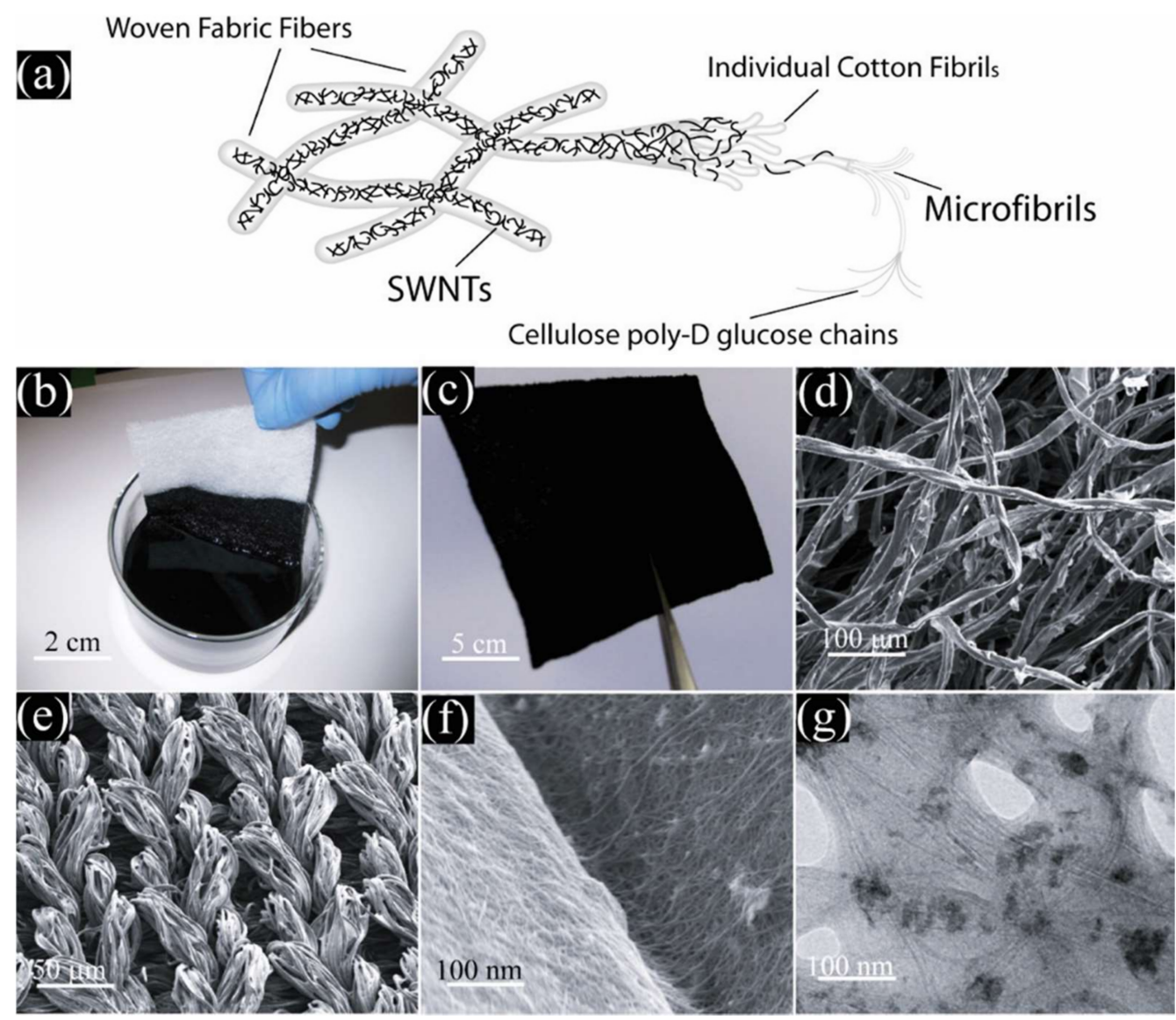

Figure 7. Fabrication of porous textile conductors. (a) Schematic of SWNTs wrapped around cellulose fibers. (b) Textile dipped into an aqueous SWNT ink followed by drying to prepare conductive textiles. (c) Digital image of a thin, textile conductor based on a fabric sheet with $100 \%$ cotton. (d) Scanning electron microscope (SEM) micrograph of coated cotton showing the macroporosity. (e) SEM image of nanotube coated fabric. (f) High-magnification SEM image displays the conformal coating of SWNT casing and connecting fabric fibers. (g) Transmission electron microscope (TEM) micrograph of SWNTs coated on cotton fibers. Reprinted with permission from [89]. Copyright (2010) American Chemical Society.

Recently, transfer printing [90], printable elastic conductors [91-93], and conductive liquid metals [94,95] are becoming popular in this area. Printable elastic conductors made from silver flakes, a fluorine rubber, and a fluorine surfactant were developed by Matsuhisa et al. [96] at the University of Tokyo in Japan. The fluorine surfactant creates a key constituent that leads to the formation of surface-localized conductive networks in the printed elastic conductor, creating high conductivity and stretch ability.

3D printing, as a competent additive manufacturing technique, can quickly and precisely fabricate an arbitrary and complicated assembly that is desired for the serial production of conductive connectors 
for e-textiles. Recently, Gao et al. [97] 3D-printed (shown in Figure 8) boron nitride (BN)/poly(vinyl alcohol) (PVA) conductive composite fibers for efficient personal cooling with thermal regulation textiles. The highly aligned printed BN nanosheets in the microfibers performed heat transfer efficiently with the surrounding medium.

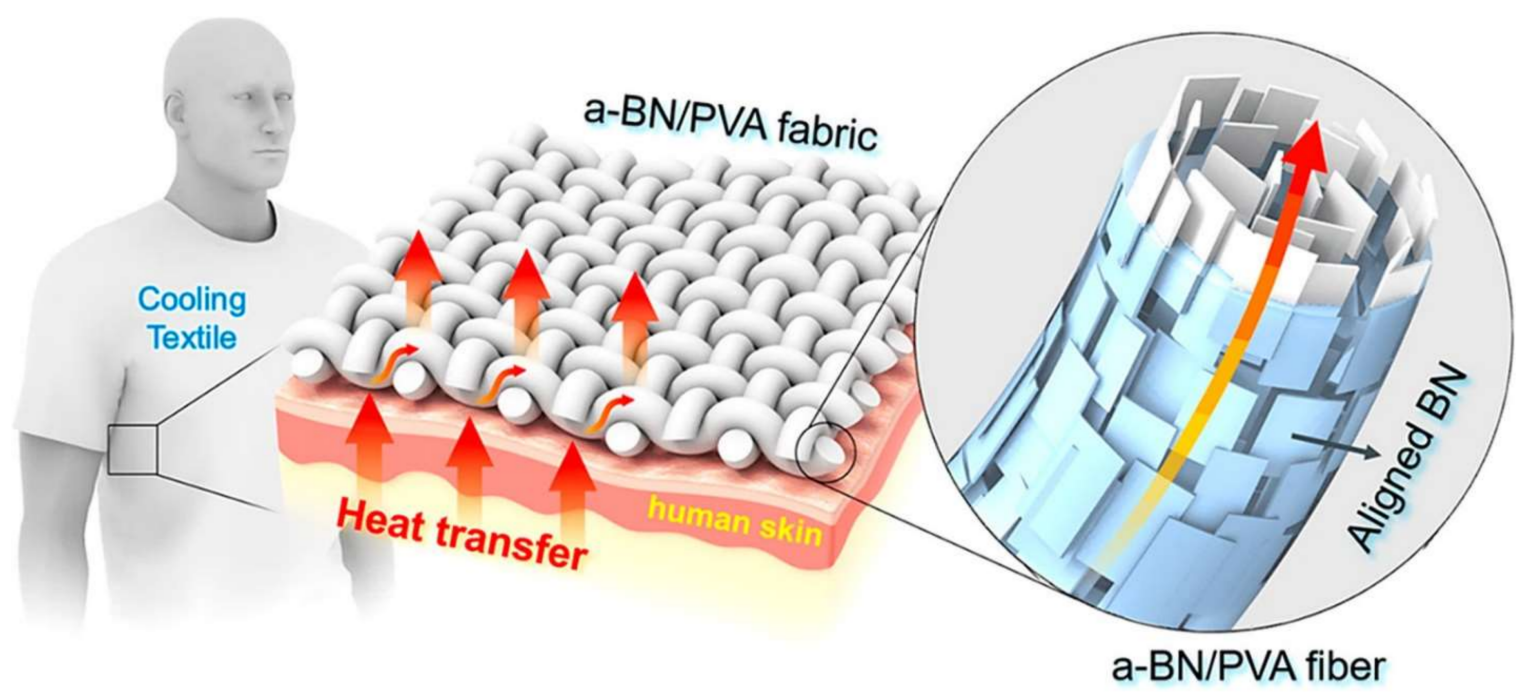

Figure 8. Graphic presentation of the thermal regulation textile. The textile is composed of thermally conductive composite fibers with well-aligned and interconnected BN nanosheets embedded in the PVA polymer matrix. Reprinted with permission from [97]. Copyright (2017) American Chemical Society.

Ota et al. [98] demonstrated a 3D-printed electronics fabrication scheme using flexible materials to provide personalized wearable designs for maximum comfort and long-term use. To realize the personalized ear-shaped mold and 3D circuits, they introduced a solid 3D printing technique to embed Galinstan liquid metal microchannels inside a stretchable polyurethane substrate. The base substrate comprises microchannels for liquid metal interconnects as well as shafts where integrated chips (ICs) were incorporated. These liquid metal interconnects and the $3 \mathrm{D}$ printing arrangements have full potential to be used in e-textiles.

\section{Textiles in Advanced Health Care}

The enrichment of efficient, independent, multifunctional, actuation, mechanical, and biosensing arrangements in textiles is possible by lab-on-fiber technology [99]. Those multifunctional smart sensors integrated with individual fibers exchange information about analysis and provide efficient sensing. For example, in the case of a plasmonic sensor, a surface plasmon propagates along a metal/dielectric interface in an optical fiber upon excitation [100]. The variation in the optical refractive index of an analyte near the metal layer significantly enhances phase matching and thus changes the spectral response of the optical fibers; thereby, sensing occurs [101].

Environmental parameter (such as heat, humidity, and pressure) sensors have already been attached in textiles [102]. Henceforth, 3D printing and microfluidics can be combined in fabric-based point-of-care diagnostic applications $[103,104]$. Integrated with light emitting diodes (LEDs), these fabrics can be used for visual sensing [105]. The programmable delivery and release of therapeutic drugs is also possible by combining drug-loaded micro/nanoparticles with e-textiles [106,107].

Recently, Prof. Ali Khademhosseini's research group at Harvard Medical School, USA, has developed an actively controlled wound dressing using composite fibers attached to a heating element and enclosed by a hydrogel layer comprised of thermoresponsive drugs [108]. They have assembled the drug- and biological-factor-loaded fibers using textiles and have created a flexible and wearable wound dressing. Such fibers can individually address the programmable release of different drugs 
with a collective temporal profile. In a recent study, it has been demonstrated that sensors can be integrated with textiles such that they are wearable and can be used to monitor biochemical changes in body fluids, such as sweat [23]. Caldara et al. [109] reported the efficient monitoring of sweat $\mathrm{pH}$ by a wearable sensor based on a cotton fabric treated with an organically modified silicate and miniaturized and low-power electronics with wireless interfaces. In a separate study, a fully textile, wearable organic electrochemical transistor (OECT) sensor for the detection of biomarkers in external body fluids was developed by Gualandi et al. without using an invasive electrode [110].

\section{Conclusions and Future Scopes}

E-textiles, as flexible substrates, are suitable for applications in various areas, such as wearable sensors. Such textiles can be used for sensing, computing, actuating, and communicating when integrated with electronics or photonics. Electronic counterparts can be incorporated with apparel, and a wearable scheme can lead to more adaptable, multipurpose uses. A user can adjust their look and obtain valuable information based on environmental changes and their own specific preferences. Therapeutic drugs and biological factors using textiles are also of importance.

Though the recent advances in e-textiles have been remarkable, their electrical enactment and device arrangements are still inadequate for end user level. In addition, they are typically not waterproof nor weather-resistant and cannot be washed. Concerns regarding the toxicity of the nanomaterials used in fabrics along with the commercial trends in the global textile market need more attention. To resolve these issues, innovative designs of new functional soft materials and novel processing expertise and knowledge have been introduced.

With the high amount of research being conducted in emerging textile technology, together with research on stretchable and printed electronics, conductive inks, wearable, printed, and flexible sensors, energy storage, and so on, e-textiles have managed to gain a substantial amount of attention. The use of typical manufacturing techniques to produce textile-based sensors, energy harvesting devices, and other smart electronics as well as techniques that allow for easy integration with wearable garments, which has great mass-market potential, are the main motivations of this review.

Acknowledgments: Kunal Mondal wants to acknowledge Professor Ashutosh Sharma (2015 to till date), the Honorable Secretary to the Department of Science and Technology, India, for his constant support and inspiration to many generations of colloid and surface scientists and engineers and his enormous contribution to the nanoscience and nanotechnology of India and of the world.

Conflicts of Interest: The author declare no conflict of interest

\section{References}

1. Stoppa, M.; Chiolerio, A. Wearable Electronics and Smart Textiles: A Critical Review. Sensors 2014, 14, 11957-11992. [CrossRef] [PubMed]

2. Castano, L.M.; Flatau, A.B. Smart fabric sensors and e-textile technologies: A review. Smart Mater. Struct. 2014, 23, 053001. [CrossRef]

3. Kamiya, R.; Cheeseman, B.A.; Popper, P.; Chou, T.-W. Some recent advances in the fabrication and design of three-dimensional textile preforms: A review. Compos. Sci. Technol. 2000, 60, 33-47. [CrossRef]

4. Carpi, F.; DeRossi, D. Electroactive Polymer-Based Devices for e-Textiles in Biomedicine. IEEE Trans. Inf. Technol. Biomed. 2005, 9, 295-318. [CrossRef] [PubMed]

5. Lee, J.B.; Subramanian, V. Weave Patterned Organic Transistors on Fiber for E-Textiles. IEEE Trans. Electron Devices 2005, 52, 269-275. [CrossRef]

6. Kennedy, T.F.; Fink, P.W.; Chu, A.W.; Champagne, N.J.; Lin, G.Y.; Khayat, M.A. Body-Worn E-Textile Antennas: The Good, the Low-Mass, and the Conformal. IEEE Trans. Antennas Propag. 2009, 57, 910-918. [CrossRef]

7. Bonderover, E.; Wagner, S. A Woven Inverter Circuit for e-Textile Applications. IEEE Electron Device Lett. 2004, 25, 295-297. [CrossRef] 
8. Hamedi, M.; Herlogsson, L.; Crispin, X.; Marcilla, R.; Berggren, M.; Inganäs, O. Fiber-Embedded Electrolyte-Gated Field-Effect Transistors for e-Textiles. Adv. Mater. 2009, 21, 573-577. [CrossRef] [PubMed]

9. López, G.; Custodio, V.; Moreno, J.I. LOBIN: E-Textile and Wireless-Sensor-Network-Based Platform for Healthcare Monitoring in Future Hospital Environments. IEEE Trans. Inf. Technol. Biomed. 2010, 14, 1446-1458. [CrossRef] [PubMed]

10. Buechley, L.; Eisenberg, M. Fabric PCBs, electronic sequins, and socket buttons: Techniques for e-textile craft. Pers. Ubiquitous Comput. 2009, 13, 133-150. [CrossRef]

11. Bayram, Y.; Zhou, Y.; Shim, B.S.; Xu, S.; Zhu, J.; Kotov, N.A.; Volakis, J.L. E-Textile Conductors and Polymer Composites for Conformal Lightweight Antennas. IEEE Trans. Antennas Propag. 2010, 58, 2732-2736. [CrossRef]

12. Crawford, C. The E-Textile eVolution. AATCC Rev. 2017, 17, 30-35. [CrossRef]

13. Li, X.; Sun, Y. WearETE: A Scalable Wearable E-Textile Triboelectric Energy Harvesting System for Human Motion Scavenging. Sensors 2017, 17, 2649. [CrossRef] [PubMed]

14. Liu, S.; Tong, J.; Yang, C.; Li, L. Smart E-textile: Resistance properties of conductive knitted fabric-Single pique. Text. Res. J. 2017, 87, 1669-1684. [CrossRef]

15. Brosteaux, D.; Fabrice, A.; Gonzalez, M.; Vanfleteren, J. Design and Fabrication of Elastic Interconnections for Stretchable Electronic Circuits. IEEE Electron Device Lett. 2007, 28, 552-554. [CrossRef]

16. Sibinski, M.; Jakubowska, M.; Sloma, M. Flexible Temperature Sensors on Fibers. Sensors 2010, 10, 7934-7946. [CrossRef] [PubMed]

17. Mattana, G.; Kinkeldei, T.; Leuenberger, D.; Ataman, C.; Ruan, J.J.; Molina-Lopez, F.; Quintero, A.V.; Nisato, G.; Troster, G.; Briand, D.; et al. Woven Temperature and Humidity Sensors on Flexible Plastic Substrates for E-Textile Applications. IEEE Sens. J. 2013, 13, 3901-3909. [CrossRef]

18. Krehel, M.; Wolf, M.; Boesel, L.F.; Rossi, R.M.; Bona, G.-L.; Scherer, L.J. Development of a luminous textile for reflective pulse oximetry measurements. Biomed. Opt. Express 2014, 5, 2537-2547. [CrossRef] [PubMed]

19. Cochrane, C.; Mordon, S.R.; Lesage, J.C.; Koncar, V. New design of textile light diffusers for photodynamic therapy. Mater. Sci. Eng. C 2013, 33, 1170-1175. [CrossRef] [PubMed]

20. McLaren, R.; Joseph, F.; Baguley, C.; Taylor, D. A review of e-textiles in neurological rehabilitation: How close are we? J. NeuroEng. Rehabil. 2016, 13. [CrossRef] [PubMed]

21. Tosi, D.; Poeggel, S.; Iordachita, I.; Schena, E. Fiber Optic Sensors for Biomedical Applications. In Opto-Mechanical Fiber Optic Sensors; Elsevier: New York, NY, USA, 2018; pp. 301-333, ISBN 978-0-12-803131-5.

22. Coyle, S.; Wu, Y.; Lau, K.-T.; Brady, S.; Wallace, G.; Diamond, D. Bio-sensing textiles-Wearable Chemical Biosensors for Health Monitoring. In Proceedings of the 4th International Workshop on Wearable and Implantable Body Sensor Networks (BSN 2007), Aachen, Germany, 26-28 March 2007; Leonhardt, S., Falck, T., Mähönen, P., Eds.; Springer: Berlin, Germany, 2007; Volume 13, pp. 35-39.

23. Morris, D.; Coyle, S.; Wu, Y.; Lau, K.T.; Wallace, G.; Diamond, D. Bio-sensing textile based patch with integrated optical detection system for sweat monitoring. Sens. Actuators B Chem. 2009, 139, 231-236. [CrossRef]

24. Haghdoost, F.; Mottaghitalab, V.; Haghi, A.K. Comfortable textile-based electrode for wearable electrocardiogram. Sens. Rev. 2015, 35, 20-29. [CrossRef]

25. Magenes, G.; Curone, D.; Secco, E.L.; Bonfiglio, A. Biosensing and environmental sensing for emergency and protection e-textiles. Conf. Proc. IEEE Eng. Med. Biol. Soc. 2011, 2011, 8365-8368. [CrossRef] [PubMed]

26. Nusser, M.; Senner, V. High-tech-textiles in competition sports. Procedia Eng. 2010, 2, 2845-2850. [CrossRef]

27. Paradiso, R.; Belloc, C.; Loriga, G.; Taccini, N. Wearable healthcare systems, new frontiers of e-textile. Stud. Health Technol. Inform. 2005, 117, 9-16. [PubMed]

28. Brisson, P.; Baurley, S.; Pelissier, Y.; Esteves, F. Space technology moves textiles "smart". Smart Mater. Bull. 2002, 2002, 9-10. [CrossRef]

29. Richard, G.T.; Kafai, Y.B. Making physical and digital games with e-textiles: A workshop for youth making responsive wearable games and controllers. In Proceedings of the 14th International Conference on Interaction Design and Children, Boston, MA, USA, 21-24 June 2015; ACM Press: New York, NY, USA, 2015; pp. 399-402.

30. Berzowska, J. Electronic Textiles: Wearable Computers, Reactive Fashion, and Soft Computation. Textile 2005, 3, 58-75. [CrossRef] 
31. Service, R.F. Technology: Electronic Textiles Charge Ahead. Science 2003, 301, 909-911. [CrossRef] [PubMed]

32. Wang, Y.; Yu, W.; Wang, F. Structural design and physical characteristics of modified ring-spun yarns intended for e-textiles: A comparative study. Text. Res. J. 2017, 004051751774115. [CrossRef]

33. Coyle, S.; Diamond, D. Smart Nanotextiles: Materials and Their Application. In Encyclopedia of Materials: Science and Technology; Elsevier: New York, NY, USA, 2010; pp. 1-5. ISBN 978-0-08-043152-9.

34. Zeng, W.; Shu, L.; Li, Q.; Chen, S.; Wang, F.; Tao, X.-M. Fiber-Based Wearable Electronics: A Review of Materials, Fabrication, Devices, and Applications. Adv. Mater. 2014, 26, 5310-5336. [CrossRef] [PubMed]

35. Ghahremani Honarvar, M.; Latifi, M. Overview of wearable electronics and smart textiles. J. Text. Inst. 2017, 108, 631-652. [CrossRef]

36. Meoli, D. Interactive Electronic Textiles: Technologies, Applications, Opportunities, and Market Potential; North Carolina State University: Raleigh, NC, USA, 2002.

37. Sarif Ullah Patwary, M.S. Smart Textiles and Nano-Technology: A General Overview. J. Text. Sci. Eng. 2015, 5, 1000181. [CrossRef]

38. Rivero, P.J.; Urrutia, A.; Goicoechea, J.; Arregui, F.J. Nanomaterials for Functional Textiles and Fibers. Nanoscale Res. Lett. 2015, 10. [CrossRef] [PubMed]

39. Vigneshwaran, N.; Kumar, S.; Kathe, A.A.; Varadarajan, P.V.; Prasad, V. Functional finishing of cotton fabrics using zinc oxide-soluble starch nanocomposites. Nanotechnology 2006, 17, 5087-5095. [CrossRef]

40. Colleoni, C.; Esposito, F.; Guido, E.; Migani, V.; Trovato, V.; Rosace, G. Ceramic coatings for water-repellent textiles. In Proceedings of the IOP Conference Series: Materials Science and Engineering, Bali, Indonesia, 25-26 October 2017; IOP Publishing: Bristol, UK, 2017; Volume 254, p. 122002. [CrossRef]

41. Parvinzadeh Gashti, M.; Pakdel, E.; Alimohammadi, F. Nanotechnology-based coating techniques for smart textiles. In Active Coatings for Smart Textiles; Elsevier: New York, NY, USA, 2016; pp. 243-268, ISBN 978-0-08-100263-6.

42. Ferrero, F.; Periolatto, M.; Tempestini, L. Water and Oil Repellent Finishing of Textiles by UV Curing: Evaluation of the Influence of Scaled-up Process Parameters. Coatings 2017, 7, 60. [CrossRef]

43. Salmeia, K.; Gaan, S.; Malucelli, G. Recent Advances for Flame Retardancy of Textiles Based on Phosphorus Chemistry. Polymers 2016, 8, 319. [CrossRef]

44. Tsuzuki, T.; Wang, X. Nanoparticle Coatings for UV Protective Textiles. Res. J. Text. Appar. 2010, 14, 9-20. [CrossRef]

45. Wu, B.; Zhang, B.; Wu, J.; Wang, Z.; Ma, H.; Yu, M.; Li, L.; Li, J. Electrical Switchability and Dry-Wash Durability of Conductive Textiles. Sci. Rep. 2015, 5. [CrossRef] [PubMed]

46. Mishra, R.; Militky, J.; Baheti, V.; Huang, J.; Kale, B.; Venkataraman, M.; Bele, V.; Arumugam, V.; Zhu, G.; Wang, Y. The production, characterization and applications of nanoparticles in the textile industry. Text. Prog. 2014, 46, 133-226. [CrossRef]

47. Saad, S.R.; Mahmed, N.; Abdullah, M.M.A.B.; Sandu, A.V. Self-Cleaning Technology in Fabric: A Review. In Proceedings of the IOP Conference Series: Materials Science and Engineering, Iasi, Romania, 19-20 May 2016; IOP Publishing: Bristol, UK, 2016; Volume 133, p. 012028. [CrossRef]

48. Zhang, D.; Miao, M.; Niu, H.; Wei, Z. Core-Spun Carbon Nanotube Yarn Supercapacitors for Wearable Electronic Textiles. ACS Nano 2014, 8, 4571-4579. [CrossRef] [PubMed]

49. Shen, L.; Che, Q.; Li, H.; Zhang, X. Mesoporous $\mathrm{NiCo}_{2} \mathrm{O}_{4}$ Nanowire Arrays Grown on Carbon Textiles as Binder-Free Flexible Electrodes for Energy Storage. Adv. Funct. Mater. 2014, 24, 2630-2637. [CrossRef]

50. Karim, N.; Afroj, S.; Malandraki, A.; Butterworth, S.; Beach, C.; Rigout, M.; Novoselov, K.S.; Casson, A.J.; Yeates, S.G. All inkjet-printed graphene-based conductive patterns for wearable e-textile applications. J. Mater. Chem. C 2017, 5, 11640-11648. [CrossRef]

51. Cai, G.; Xu, Z.; Yang, M.; Tang, B.; Wang, X. Functionalization of cotton fabrics through thermal reduction of graphene oxide. Appl. Surf. Sci. 2017, 393, 441-448. [CrossRef]

52. Ren, J.; Wang, C.; Zhang, X.; Carey, T.; Chen, K.; Yin, Y.; Torrisi, F. Environmentally-friendly conductive cotton fabric as flexible strain sensor based on hot press reduced graphene oxide. Carbon 2017, 111, 622-630. [CrossRef]

53. Huang, Q.; Liu, L.; Wang, D.; Liu, J.; Huang, Z.; Zheng, Z. One-step electrospinning of carbon nanowebs on metallic textiles for high-capacitance supercapacitor fabrics. J. Mater. Chem. A 2016, 4, 6802-6808. [CrossRef]

54. Joseph, J.; Nair, S.V.; Menon, D. Integrating Substrateless Electrospinning with Textile Technology for Creating Biodegradable Three-Dimensional Structures. Nano Lett. 2015, 15, 5420-5426. [CrossRef] [PubMed] 
55. Yun, Y.J.; Hong, W.G.; Kim, W.-J.; Jun, Y.; Kim, B.H. A Novel Method for Applying Reduced Graphene Oxide Directly to Electronic Textiles from Yarns to Fabrics. Adv. Mater. 2013, 25, 5701-5705. [CrossRef] [PubMed]

56. Brown, P.S.; Bhushan, B. Mechanically durable, superoleophobic coatings prepared by layer-by-layer technique for anti-smudge and oil-water separation. Sci. Rep. 2015, 5. [CrossRef] [PubMed]

57. Yetisen, A.K.; Qu, H.; Manbachi, A.; Butt, H.; Dokmeci, M.R.; Hinestroza, J.P.; Skorobogatiy, M.; Khademhosseini, A.; Yun, S.H. Nanotechnology in Textiles. ACS Nano 2016, 10, 3042-3068. [CrossRef] [PubMed]

58. Du, D.; Tang, Z.; Ouyang, J. Highly washable e-textile prepared by ultrasonic nanosoldering of carbon nanotubes onto polymer fibers. J. Mater. Chem. C 2018, 6, 883-889. [CrossRef]

59. Karim, N.; Afroj, S.; Tan, S.; He, P.; Fernando, A.; Carr, C.; Novoselov, K.S. Scalable Production of Graphene-Based Wearable E-Textiles. ACS Nano 2017, 11, 12266-12275. [CrossRef] [PubMed]

60. Kaushik, V.; Lee, J.; Hong, J.; Lee, S.; Lee, S.; Seo, J.; Mahata, C.; Lee, T. Textile-Based Electronic Components for Energy Applications: Principles, Problems, and Perspective. Nanomaterials 2015, 5, 1493-1531. [CrossRef] [PubMed]

61. Dong, L. Toward optoelectronic textiles. SPIE Newsroom 2012. [CrossRef]

62. Gao, Y.; Li, H.; Liu, J. Direct Writing of Flexible Electronics through Room Temperature Liquid Metal Ink. PLOS ONE 2012, 7, e45485. [CrossRef] [PubMed]

63. Eom, J.; Jaisutti, R.; Lee, H.; Lee, W.; Heo, J.-S.; Lee, J.-Y.; Park, S.K.; Kim, Y.-H. Highly Sensitive Textile Strain Sensors and Wireless User-Interface Devices Using All-Polymeric Conducting Fibers. ACS Appl. Mater. Interfaces 2017, 9, 10190-10197. [CrossRef] [PubMed]

64. Mazzoldi, A.; De Rossi, D.; Lorussi, F.; Scilingo, E.P.; Paradiso, R. Smart textiles for wearable motion capture systems. AUTEX Res. J. 2002, 2, 108-111.

65. Lorussi, F.; Scilingo, E.P.; Tesconi, M.; Tognetti, A.; DeRossi, D. Strain Sensing Fabric for Hand Posture and Gesture Monitoring. IEEE Trans. Inf. Technol. Biomed. 2005, 9, 372-381. [CrossRef] [PubMed]

66. Meyer, J.; Lukowicz, P.; Troster, G. Textile Pressure Sensor for Muscle Activity and Motion Detection. In Proceedings of the 10th IEEE International Symposium on Wearable Computers, Montreux, Switzerland, 11-14 October 2006; pp. 69-72.

67. Lee, J.; Kwon, H.; Seo, J.; Shin, S.; Koo, J.H.; Pang, C.; Son, S.; Kim, J.H.; Jang, Y.H.; Kim, D.E.; et al. Conductive Fiber-Based Ultrasensitive Textile Pressure Sensor for Wearable Electronics. Adv. Mater. 2015, 27, 2433-2439. [CrossRef] [PubMed]

68. Wang, L.; Loh, K.J. Wearable carbon nanotube-based fabric sensors for monitoring human physiological performance. Smart Mater. Struct. 2017, 26, 055018. [CrossRef]

69. Li, Y.-Q.; Huang, P.; Zhu, W.-B.; Fu, S.-Y.; Hu, N.; Liao, K. Flexible wire-shaped strain sensor from cotton thread for human health and motion detection. Sci. Rep. 2017, 7, 45013. [CrossRef] [PubMed]

70. Fernández-Garcia, R.; Gil, I. An Alternative Wearable Tracking System Based on a Low-Power Wide-Area Network. Sensors 2017, 17, 592. [CrossRef] [PubMed]

71. Zhu, S.; Langley, R. Dual-Band Wearable Textile Antenna on an EBG Substrate. IEEE Trans. Antennas Propag. 2009, 57, 926-935. [CrossRef]

72. Locher, I.; Klemm, M.; Kirstein, T.; Trster, G. Design and Characterization of Purely Textile Patch Antennas. IEEE Trans. Adv. Packag. 2006, 29, 777-788. [CrossRef]

73. Karimi, R.; Mohtaram, F.; Mottaghitalab, V.; Khajeh Mehrizi, M. Development of wearable rectangular textile antenna and investigation of its performance under bent condition at different angles. J. Ind. Text. 2018, 47, 765-780. [CrossRef]

74. Hertleer, C.; Tronquo, A.; Rogier, H.; Van Langenhove, L. The Use of Textile Materials to Design Wearable Microstrip Patch Antennas. Text. Res. J. 2008, 78, 651-658. [CrossRef]

75. Salvado, R.; Loss, C.; Gonçalves, R.; Pinho, P. Textile Materials for the Design of Wearable Antennas: A Survey. Sensors 2012, 12, 15841-15857. [CrossRef] [PubMed]

76. Hertleer, C.; Van Laere, A.; Rogier, H.; Van Langenhove, L. Influence of Relative Humidity on Textile Antenna Performance. Text. Res. J. 2010, 80, 177-183. [CrossRef]

77. Wang, Z.; Zhang, L.; Bayram, Y.; Volakis, J.L. Embroidered Conductive Fibers on Polymer Composite for Conformal Antennas. IEEE Trans. Antennas Propag. 2012, 60, 4141-4147. [CrossRef] 
78. European Association on Antennas and Propagation (Ed.) Implementation and wireless readout of passive UHF RFID strain sensor tags based on electro-textile antennas. In Proceedings of the 2015 9th European Conference on Antennas and Propagation (EuCAP 2015), Lisbon, Portugal, 13-17 April 2015; IEEE: Piscataway, NJ, USA, 2015.

79. European Association on Antennas and Propagation (Ed.) Smart Textiles for Wearable Motion Capture Systems; IEEE: Piscataway, NJ, USA, 2013; ISBN 978-88-907018-1-8.

80. Tudor, J.; Vardaxoglou, J.C.; Torah, R.; Li, Y.; Whittow, W.G.; Chauraya, A.; Beeby, S.; Yang, K. Inkjet printed dipole antennas on textiles for wearable communications. IET Microw. Antennas Propag. 2013, 7, 760-767. [CrossRef]

81. Kaufmann, T.; Fumeaux, C. Wearable Textile Half-Mode Substrate-Integrated Cavity Antenna Using Embroidered Vias. IEEE Antennas Wirel. Propag. Lett. 2013, 12, 805-808. [CrossRef]

82. Rizwan, M.; Khan, M.W.A.; Sydanheimo, L.; Virkki, J.; Ukkonen, L. Flexible and Stretchable Brush-Painted Wearable Antenna on a Three-Dimensional (3-D) Printed Substrate. IEEE Antennas Wirel. Propag. Lett. 2017, 16, 3108-3112. [CrossRef]

83. Agneessens, S.; Bozzi, M.; Moro, R.; Rogier, H. Wearable textile antenna in substrate integrated waveguide technology. Electron. Lett. 2012, 48, 985-987. [CrossRef]

84. Huang, Y.; Hu, H.; Huang, Y.; Zhu, M.; Meng, W.; Liu, C.; Pei, Z.; Hao, C.; Wang, Z.; Zhi, C. From Industrially Weavable and Knittable Highly Conductive Yarns to Large Wearable Energy Storage Textiles. ACS Nano 2015, 9, 4766-4775. [CrossRef] [PubMed]

85. Jost, K.; Dion, G.; Gogotsi, Y. Textile energy storage in perspective. J. Mater. Chem. A 2014, 2, 10776. [CrossRef]

86. Zhai, S.; Karahan, H.E.; Wei, L.; Qian, Q.; Harris, A.T.; Minett, A.I.; Ramakrishna, S.; Ng, A.K.; Chen, Y. Textile energy storage: Structural design concepts, material selection and future perspectives. Energy Storage Mater. 2016, 3, 123-139. [CrossRef]

87. Chai, Z.; Zhang, N.; Sun, P.; Huang, Y.; Zhao, C.; Fan, H.J.; Fan, X.; Mai, W. Tailorable and Wearable Textile Devices for Solar Energy Harvesting and Simultaneous Storage. ACS Nano 2016, 10, 9201-9207. [CrossRef] [PubMed]

88. Agcayazi, T.; Chatterjee, K.; Bozkurt, A.; Ghosh, T.K. Flexible Interconnects for Electronic Textiles. Adv. Mater. Technol. 2018, 1700277. [CrossRef]

89. Hu, L.; Pasta, M.; La Mantia, F.; Cui, L.; Jeong, S.; Deshazer, H.D.; Choi, J.W.; Han, S.M.; Cui, Y. Stretchable, Porous, and Conductive Energy Textiles. Nano Lett. 2010, 10, 708-714. [CrossRef] [PubMed]

90. Yoon, J.; Jeong, Y.; Kim, H.; Yoo, S.; Jung, H.S.; Kim, Y.; Hwang, Y.; Hyun, Y.; Hong, W.-K.; Lee, B.H.; et al. Robust and stretchable indium gallium zinc oxide-based electronic textiles formed by cilia-assisted transfer printing. Nat. Commun. 2016, 7, 11477. [CrossRef] [PubMed]

91. Grancarić, A.M.; Jerković, I.; Koncar, V.; Cochrane, C.; Kelly, F.M.; Soulat, D.; Legrand, X. Conductive polymers for smart textile applications. J. Ind. Text. 2017, 152808371769936. [CrossRef]

92. Rai, P.; Lee, J.; Mathur, G.N.; Varadan, V.K. Carbon nanotubes polymer nanoparticles inks for healthcare textile. In Nanosystems in Engineering and Medicine; Choi, S.H., Choy, J.-H., Lee, U., Varadan, V.K., Eds.; International Society for Optics and Photonics: Bellingham, WA, USA, 2012; p. 854822.

93. Kaynak, A.; Foitzik, R. Methods of Coating Textiles with Soluble Conducting Polymers. Res. J. Text. Appar. 2011, 15, 107-113. [CrossRef]

94. Khondoker, M.A.H.; Sameoto, D. Fabrication methods and applications of microstructured gallium based liquid metal alloys. Smart Mater. Struct. 2016, 25, 093001. [CrossRef]

95. Zhu, S.; So, J.-H.; Mays, R.; Desai, S.; Barnes, W.R.; Pourdeyhimi, B.; Dickey, M.D. Ultrastretchable Fibers with Metallic Conductivity Using a Liquid Metal Alloy Core. Adv. Funct. Mater. 2013, 23, 2308-2314. [CrossRef]

96. Matsuhisa, N.; Kaltenbrunner, M.; Yokota, T.; Jinno, H.; Kuribara, K.; Sekitani, T.; Someya, T. Printable elastic conductors with a high conductivity for electronic textile applications. Nat. Commun. 2015, 6. [CrossRef] [PubMed]

97. Gao, T.; Yang, Z.; Chen, C.; Li, Y.; Fu, K.; Dai, J.; Hitz, E.M.; Xie, H.; Liu, B.; Song, J.; et al. Three-Dimensional Printed Thermal Regulation Textiles. ACS Nano 2017, 11, 11513-11520. [CrossRef] [PubMed]

98. Ota, H.; Chao, M.; Gao, Y.; Wu, E.; Tai, L.-C.; Chen, K.; Matsuoka, Y.; Iwai, K.; Fahad, H.M.; Gao, W.; et al. 3D Printed “Earable" Smart Devices for Real-Time Detection of Core Body Temperature. ACS Sens. 2017, 2, 990-997. [CrossRef] [PubMed] 
99. Consales, M.; Ricciardi, A.; Crescitelli, A.; Esposito, E.; Cutolo, A.; Cusano, A. Lab-on-Fiber Technology: Toward Multifunctional Optical Nanoprobes. ACS Nano 2012, 6, 3163-3170. [CrossRef] [PubMed]

100. Esmaeilzadeh, H.; Rivard, M.; Arzi, E.; Légaré, F.; Hassani, A. Smart textile plasmonic fiber dew sensors. Opt. Express 2015, 23, 14981-14992. [CrossRef] [PubMed]

101. Zhang, Z.; Yang, J.; He, X.; Zhang, J.; Huang, J.; Chen, D.; Han, Y. Plasmonic Refractive Index Sensor with High Figure of Merit Based on Concentric-Rings Resonator. Sensors 2018, 18, 116. [CrossRef] [PubMed]

102. Capineri, L. Resistive Sensors with Smart Textiles for Wearable Technology: From Fabrication Processes to Integration with Electronics. Procedia Eng. 2014, 87, 724-727. [CrossRef]

103. Grimmelsmann, N.; Martens, Y.; Schäl, P.; Meissner, H.; Ehrmann, A. Mechanical and Electrical Contacting of Electronic Components on Textiles by 3D Printing. Procedia Technol. 2016, 26, 66-71. [CrossRef]

104. Nilghaz, A.; Ballerini, D.R.; Shen, W. Exploration of microfluidic devices based on multi-filament threads and textiles: A review. Biomicrofluidics 2013, 7, 051501. [CrossRef] [PubMed]

105. Choi, S.; Kwon, S.; Kim, H.; Kim, W.; Kwon, J.H.; Lim, M.S.; Lee, H.S.; Choi, K.C. Highly Flexible and Efficient Fabric-Based Organic Light-Emitting Devices for Clothing-Shaped Wearable Displays. Sci. Rep. 2017, 7. [CrossRef] [PubMed]

106. Wienforth, F.; Landrock, A.; Schindler, C.; Siegert, J.; Kirch, W. Smart Textiles: A New Drug Delivery System for Symptomatic Treatment of a Common Cold. J. Clin. Pharmacol. 2007, 47, 653-659. [CrossRef] [PubMed]

107. Sehgal, P.K.; Sripriya, R.; Senthilkumar, M. Drug delivery dressings. In Advanced Textiles for Wound Care; Elsevier: New York, NY, USA, 2009; pp. 223-253. ISBN 978-1-84569-271-1.

108. Mostafalu, P.; Kiaee, G.; Giatsidis, G.; Khalilpour, A.; Nabavinia, M.; Dokmeci, M.R.; Sonkusale, S.; Orgill, D.P.; Tamayol, A.; Khademhosseini, A. A Textile Dressing for Temporal and Dosage Controlled Drug Delivery. Adv. Funct. Mater. 2017, 27, 1702399. [CrossRef]

109. Caldara, M.; Colleoni, C.; Guido, E.; Re, V.; Rosace, G. Optical monitoring of sweat pH by a textile fabric wearable sensor based on covalently bonded litmus-3-glycidoxypropyltrimethoxysilane coating. Sens. Actuators B Chem. 2016, 222, 213-220. [CrossRef]

110. Gualandi, I.; Marzocchi, M.; Achilli, A.; Cavedale, D.; Bonfiglio, A.; Fraboni, B. Textile Organic Electrochemical Transistors as a Platform for Wearable Biosensors. Sci. Rep. 2016, 6. [CrossRef] [PubMed]

(C) 2018 by the author. Licensee MDPI, Basel, Switzerland. This article is an open access article distributed under the terms and conditions of the Creative Commons Attribution (CC BY) license (http://creativecommons.org/licenses/by/4.0/). 